\title{
Neoplasias de língua em cinco cães
}

\author{
Neoplasms of the tongue in five dogs
}

\section{Carlos Roberto Daleck ${ }^{\mathrm{I}}$ Andrigo Barboza De Nardi ${ }^{\mathrm{II}}$ Márcio César Vasconcelos Silva ${ }^{\mathrm{II}}$ Duvaldo Eurides ${ }^{\text {III }}$ Luiz Antônio Franco da Silva ${ }^{\text {IV }}$}

\begin{abstract}
- NOTA -
\section{RESUMO}

Este trabalho tem como objetivo relatar a ocorrência de cinco casos de neoplasias de língua em cães. Os sinais clínicos mais observados foram ptialismo, halitose e hiporexia. Após biópsia excisional para exame histopatológico, os resultados revelaram dois casos de melanoma, um caso de histiocitoma, um caso de fibrossarcoma e um caso de

fibrosarcoma's case the chemotherapy was associated. Two animals had suture deiscencia in the post operatory, but in these cases it wasn't necessary another surgery. About the prognostic, the patients with histiocytoma, fibrosarcoma and one with melanoma didn't present cancer recurrence either metastasis 12 months after the surgery. But in another melanoma case the patient presented skin and lungs metastasis 30 day after surgery.
\end{abstract} mastocitoma grau II, sendo que neste o proprietário não autorizou qualquer forma de tratamento. O tratamento para os demais foi a glossectomia parcial e, no caso de fibrossarcoma, associou-se a quimioterapia. Dois animais apresentaram deiscência de sutura no pós-operatório, não havendo necessidade da realização de nova intervenção. Em relação ao prognóstico, os pacientes com histiocitoma, fibrossarcoma e um com melanoma não apresentaram recidiva, nem metástase da doença 12 meses após a cirurgia. No outro caso de melanoma, o paciente apresentou metástase na pele e nos pulmões 30 dias após a ressecção cirúrgica.

Palavras-chave: doenças de cães, neoplasias de língua, oncologia.

\section{ABSTRACT}

This paper is aimed at reporting five cases of neoplasms of the tongue in dogs. The clinical signs most observed were ptyalism, halitosis and hyporexia. After excisional biopsy the histological findings revealed two cases of melanoma, one case of histiocytoma, one case of fibrosarcoma and one case of mast cell tumor grade II, but in this case the owner didn't authorize any form of treatment. The treatments for the others cases were the partial glossectomy, and in the
Key words: $d o g$ 's diseases, neoplasms of the tongues, oncology.

Os neoplasmas de língua em cães e gatos são raros, correspondendo a apenas $4 \%$ de todos os tumores de orofaringe dos animais. Conseqüentemente, pouco se conhece sobre a incidência, a epidemiologia, o tratamento e o prognóstico dessas neoplasias (CARPENTER et al., 1993).

O tumor mais comum na língua de cães e gatos é o carcinoma de células escamosas. Outros tumores descritos nessa localização em cães incluem mioblastoma de células granulares, rabdomioma, rabdomiossarcoma, hemangioma, hemangiossarcoma, mastocitoma, fibrosssarcoma, linfoma e melanoma (SCHOOFS, 1997; HARVEY, 1998; LASCELLES et al., 1998; RALLIS et al., 2001). Esses neoplasmas geralmente são dolorosos e interferem com a função da língua. Os animais podem apresentar halitose, ptialismo, dispnéia, anorexia, perda de peso, dificuldade

IDepartamento de Clínica e Cirurgia Veterinária, Universidade Estadual Paulista (UNESP), Campus de Jaboticabal. Via de Acesso Prof. Paulo Donato Castellane, s/n, Rural, 14884-900, Jaboticabal, São Paulo, Brasil. E-mail: daleck@fcav.unesp.br.

"Programa de Cirurgia Veterinária, UNESP, Campus de Jaboticabal, São Paulo, Brasil, Curso de Mestrado em Cirurgia e Anestesiologia Veterinária, Universidade de Franca (UNIFRAN), Franca, SP, Brasil.

IIIDepartamento de Medicina Veterinária, Universidade Federal de Uberlândia (UFU), MG, Brasil.

${ }^{\text {IV }}$ Departamento de Medicina Veterinária, Escola de Veterinária da Universidade Federal de Goiás, Goiânia, GO, Brasil. 
na apreensão, mastigação e ingestão de água (WITHROW, 2001).

Em cães, quando for possível a realização da ressecção cirúrgica completa, a taxa de sobrevida em um ano pode superar os $50 \%$, porém tais casos não são comuns e a taxa de sobrevida geralmente é inferior a 25\% após um ano de pós-operatório (MORRISON, 1998; WITHROW, 2001). Segundo CARPENTER et al. (1993), a cirurgia é o tratamento de eleição para estes neoplasmas, uma vez que os cães toleram bem a glossectomia parcial. Existem alguns relatos de tratamentos quimioterápicos para carcinoma de células escamosas na língua de cães utilizando cisplatina, mitoxantrona e doxorrubicina (CARPENTER et al., 1993), porém ainda não foi estabelecido um tratamento antineoplásico efetivo (MORRIS \& DOBSON, 2002).

O prognóstico dos tumores de língua varia com a localização, a classificação histológica, a velocidade de crescimento e o estadiamento clínico (CARPENTER et al., 1993). Tumores localizados na porção rostral da língua apresentam comportamento melhor por diversas razões, mas principalmente porque a detecção pode ser precoce e a intervenção cirúrgica pode ser realizada com amplas margens de segurança. Já quando o neoplasma atinge a porção caudal da língua, a chance de metastização é maior porque há nessa região um maior número de vasos sanguíneos e linfáticos (MORRISON, 1998; WITHROW, 2001).

Esta nota tem como objetivo relatar a ocorrência de neoplasma na língua de cães atendidos no Hospital Veterinário "Governador Laudo Natel”UNESP - Campus de Jaboticabal, no período compreendido entre junho de 2003 e junho de 2005.

Como procedimento de rotina durante a avaliação clínica dos pacientes com suspeita de neoplasia primária de língua, procedeu-se a anamnese, exames físicos (pesquisa do número de tumores, mensuração e localização das lesões na superfície da língua) e laboratoriais (hemograma, urinálise e mensuração da alanino aminotransferase e creatinina) e estudo radiológico da cabeça, do pescoço e do tórax nas posições ventro-dorsal, latero-lateral direita e esquerda, com o objetivo de avaliar o comprometimento de estruturas adjacentes e pesquisar a presença de metástases.

O diagnóstico sugestivo foi obtido por citologia através da impressão ou punção aspirativa com agulha fina (PAAF) e o diagnóstico definitivo através do exame histopatológico. Quando os linfonodos satélites (mandibulares e cervicais) estavam aumentados, procedeu-se a PAAF.

Em três casos, a intervenção cirúrgica foi a única forma de tratamento empregado. Após a avaliação e preparação pré-operatória, procedeu-se a exérese neoplásica com margens de segurança, respeitando os princípios da cirurgia oncológica. A síntese cirúrgica foi realizada com padrão interrompido simples e fio de náilon ${ }^{\text {3 } 3-0 . ~ E m ~ u m ~ u ́ n i c o ~ p a c i e n t e, ~ a l e ́ m ~}$ da cirurgia foi instituída a quimioterapia antineoplásica. O tratamento quimioterápico utilizado foi doxorrubicina ${ }^{\mathrm{b}}$ (30 $\mathrm{mg} \mathrm{m}^{-2}$, por via intravenosa) e ciclofosfamidac (250mg $\mathrm{m}^{-2}$, por via oral), sendo que esses medicamentos foram administrados a cada 21 dias, num total de quatro sessões.

No período pós-operatório, duas vezes ao dia, procedeu-se à anti-sepsia da linha de sutura com gluconato de clorhexidine ${ }^{\mathrm{d}} 0,12 \%$, durante 15 dias. Todos os pacientes receberam cefalexina ${ }^{\mathrm{e}}$ na dose de $30 \mathrm{mg} \mathrm{kg}^{-1}$, via oral, a cada 12 horas, durante sete dias; meloxicam ${ }^{\mathrm{f}}$ na dose de $0,1 \mathrm{mg} \mathrm{kg}^{-1}$, via oral a cada 24 horas, durante sete dias, e cloridrato de tramadol ${ }^{\mathrm{g}}$ na dose de $2 \mathrm{mg} \mathrm{kg}^{-1}$, via oral, a cada 8 horas, durante cinco dias.

O exame de histopatologia revelou dois casos de melanoma, um histiocitoma, um fibrossarcoma e um mastocitoma grau II. Em relação à distribuição anatômica, o histiocitoma localizava-se na face lateral direita, no terço médio do órgão (Figura 1A). Em um caso de melanoma, o neoplasma situava-se na face lateral esquerda envolvendo o terço rostral e médio da língua (Figura 1B); já no outro caso, a região acometida era a porção rostral e face lateral esquerda (terço médio) (Figura 1C). O caso de mastocitoma grau II envolvia a porção rostral da língua (Figura 1D). O fibrossarcoma localizava-se na face ventral, próximo ao frênulo. Radiograficamente não foi identificada nenhuma alteração pulmonar que pudesse sugerir a presença de metástase.

Dos quatro animais submetidos a glossectomia parcial, apenas dois apresentaram deiscência de sutura no pós-operatório; no entanto, em nenhum dos casos houve a necessidade de se realizar nova intervenção cirúrgica. Em relação ao prognóstico, os pacientes com histiocitoma, fibrossarcoma e um dos casos de melanoma não apresentaram recidiva, nem metástase da doença 12 meses após a intervenção cirúrgica, sendo que estes animais foram avaliados a cada três meses. Um dos pacientes com diagnóstico de melanoma apresentou metástases na pele e no pulmão 30 dias após a ressecção cirúrgica do tumor primário. No caso do mastocitoma de grau II, o proprietário não autorizou qualquer forma de tratamento.

Para descartar a possibilidade de metástases em outras estruturas da boca, deve-se realizar uma

Ciência Rural, v.37, n.2, mar-abr, 2007. 


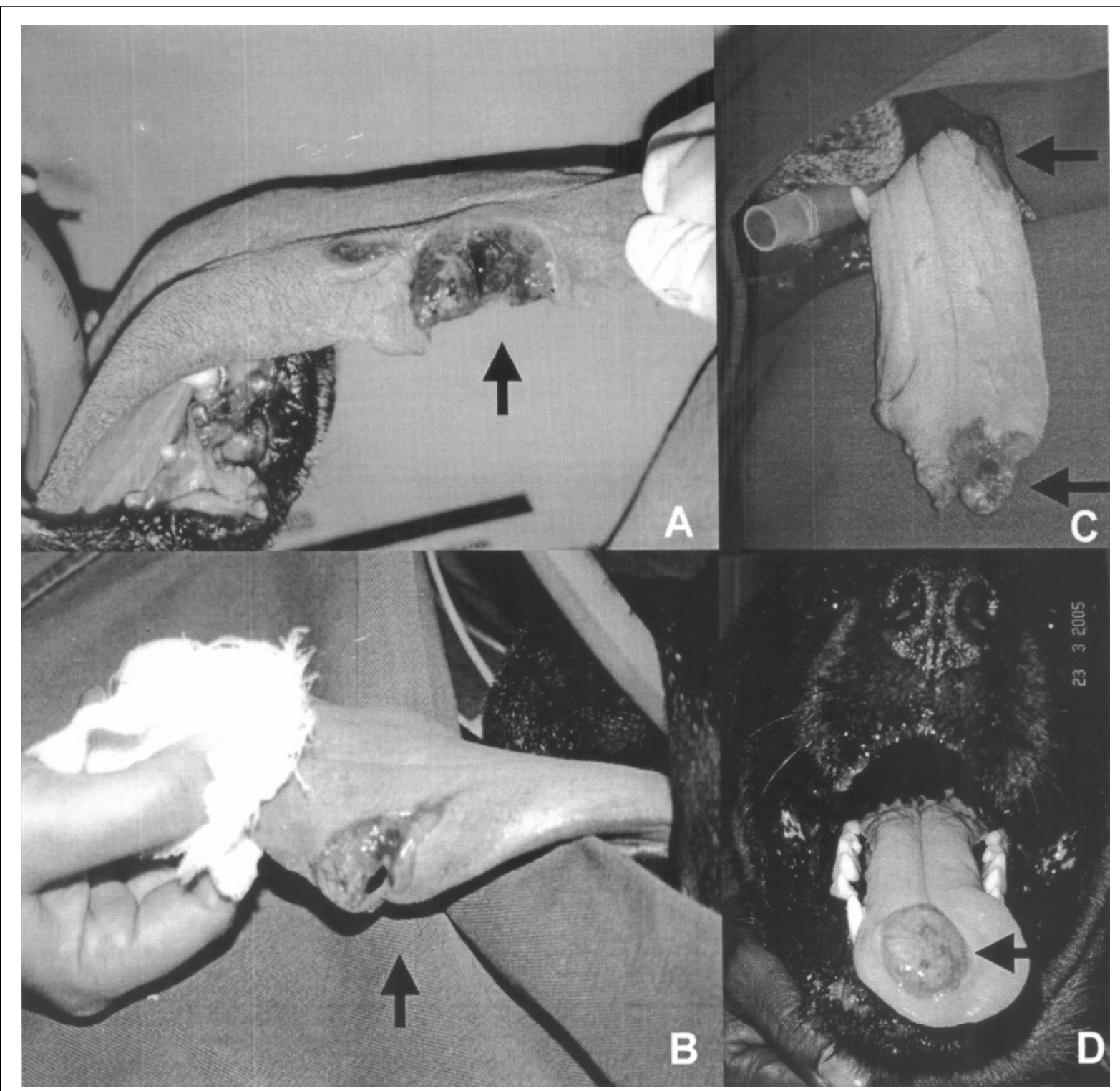

Figura 1 - Aspecto macroscópico dos neoplasmas em língua de cães. Histiocitoma na face lateral direita do terço médio da língua (A). Melanoma na face lateral esquerda, envolvendo o terço rostral e médio da língua (B). Melanoma na porção rostral e face lateral esquerda (terço médio) da língua (C). Mastocitoma grau II na porção rostral da língua (D).

inspeção rigorosa de toda a cavidade oral. A história clínica e os sinais como sialorréia, halitose e hiporexia semelhante aos encontrados por MORRISON (1998) e WITHROW (2001), associados aos exames citológico e histopatologico, foram fundamentais na definição do diagnóstico.

O tratamento de escolha para a maior parte dos casos foi a cirurgia, pois, apesar de menos comum na língua que em outro local da cavidade oral (HARVEY, 1998), as neoplasias ainda são a razão primária para as glossectomias (HEDLUND, 2002). Nenhum dos pacientes submetidos a glossectomia parcial necessitou de cuidados e alimentação especial, contrariando o preconizado por MCCARTHY (1996), o qual afirma que, para manter a preensão e a deglutição relativamente normais, as ressecções devem ser limitadas ao terço rostral da língua.

Em um dos casos de melanoma, apesar da remanescência de apenas 1/3 da porção oral da língua, o cão se adaptou perfeitamente a esta condição, apresentando normorexia cerca de 20 dias após a cirurgia, corroborando assim com as afirmações feitas por HARVEY (1998) de que cães e gatos que perdem toda a parte livre e certa porção da raiz da língua

Ciência Rural, v.37, n.2, mar-abr, 2007. 
conseguem se alimentar sugando o alimento e a água ou através do lançamento de porções de alimento até a parte aboral da língua.

HEDLUND (2002) afirma que a amputação de $40 \%$ a $60 \%$ da porção rostral da língua é geralmente bem tolerada, sendo que o que dificultaria o ato de comer seria a retirada da base da língua. Nos casos em questão, a perda de segmentgos da porção livre não impediu que os cães, após a apreensão do alimento, conseguissem deglutir.

A colocação de sonda esofágica (LEVINE et al., 1997) ou a sua colocação por faringostomia (LANTZ, 1996), para administração de alimentos, provavelmente reduziria a ocorrência de deiscência de sutura, fato este ocorrido em dois casos, pois permite que o paciente seja mantido com alimentação enteral, não prejudicando a área cirúrgica. MCCARTHY (1996) recomenda a gastrostomia, como forma de alimentação enteral a longo prazo, justificando a escolha pelo fato de que o tubo da faringostomia pode prejudicar a deglutição já debilitada.

Uma vez que a cirurgia é o tratamento de eleição para tumores na língua, há a necessidade de definir protocolos quimioterápicos para combater as metástases e aumentar a expectativa de vida desses animais (CARPENTER et al.,1993; BLACKWOOD \& DOBSON, 1996; MORRIS \& DOBSON, 2002). Para o paciente com fibrossarcoma, institui-se poliquimioterapia antineoplásica com a finalidade de erradicar micrometástases em potencial. As alterações clínicas apresentadas pelo animal foram mínimas com a utilização do protocolo proposto.

Apenas um animal com melanoma apresentou precocemente a ocorrência de metástases, e, segundo CARPENTER et al. (1993), o prognóstico para este tipo de neoplasma varia em relação à localização, à classificação histopatológica e ao seu estadiamento. Provavelmente os resultados satisfatórios obtidos com a maioria dos pacientes deste estudo, até o momento, possam ser atribuídos à localização da neoplasia, pois, segundo MORRISON(1998) e WITHROW(2001), tumores localizados na porção caudal da língua apresentam pior prognóstico, fato este atribuído ao maior número de vasos sanguíneos e linfáticos nesta região, facilitando a ocorrência de metástases.

A forma pela qual os pacientes usavam a língua para beber água foi semelhante à citada por BRAGA et al. (2004). Em vez de sugar, como comentado por MCCARTHY(1996) e HARVEY (1998), os cães colocavam a mandíbula paralela e o mais próximo da água e realizavam movimentos da mastigação, fazendo com que o líquido fosse levado até a orofaringe. A freqüência com que os animais bebiam água aumentou consideravelmente por este motivo (BRAGA et al., 2004).

Os procedimentos terapêuticos adotados para os cinco casos foram até o momento satisfatórios, pois apenas um animal com melanoma apresentou metástase precocemente. Este trabalho faz referência ao primeiro caso de histiocitoma com localização na língua.

\section{FONTES DE AQUISIÇÃO}

a- Náilon (Shalon - São Luís de Montes Belos - GO).

b- Doxolem (Zodiac - Pindamonhangaba - SP).

c- Ciclofosfamida (Neovita - Rio de Janeiro - RJ).

d- PerioGard (Colgate - São Paulo - SP)

e- $\operatorname{Keflex}^{\circledR}$ (Eli Lilly - São Paulo, SP).

f- Movatec ${ }^{\circledR}$ (Boehringer Ingelheim - São Paulo - SP)

g- Tramal ${ }^{\circledR}$ (Pharmacia - São Paulo - SP)

\section{REFERÊNCIAS}

BLACKWOOD, L.; DOBSON, J.M. Radiotherapy of oral malignant melanomas in dogs. J Am Vet Med Assoc, v.209, p.98-102, 1996.

BRAGA, F.A. et al. Laceração lingual em um cão: relato de caso. Medvep, v.2, n.8, p.239-243, 2004.

CARPENTER, L.G. et al. Squamous cell carcinoma on the tongue in 10 dogs. J Am Anim Hosp Assoc, v.29, p.17-24, 1993.

HARVEY, C.E. Cavidade oral, língua, lábios, bochechas, faringe e glândulas salivares. In: SLATTER, D. Manual de cirurgia de pequenos animais. 2.ed. São Paulo: Manole, 1998. V.1, cap.41, p.624-635.

HEDLUND, C.S. Cirurgia do sistema digestório: cirurgia da cavidade oral e da orofaringe. In: FOSSUM, T.W. Cirurgia de pequenos animais. São Paulo: Roca, 2002. Cap.16, p.222-234.

LANTZ, G.C. Colocação de uma sonda de faringostomia. In: BOJRAB, M.T. Técnicas atuais em cirurgia de pequenos animais. 3.ed. São Paulo: Roca, 1996. Cap.11, p.180-182.

LASCELLES, B.D.X. et al. Rhabdomyosarcoma of the tongue in a dog. J Small Anim Pract, v.39, n.12, p.587-591, 1998.

LEVINE, P.B. et al. Esophagostomy tubes as a method of nutritional management in cats. J Am Anim Hosp Assoc, v.33, n.3, p.405-410, 1997.

MCCARTHY, R.J. Surgery of the head and neck: lingual surgery. In: LIPOWITZ, A.J. Complications in small animal surgery: diagnosis, management, prevention. Philadelphia: Baltimore, 1996. Cap.5, p.153-155.

MORRIS, J.; DOBSON, J. Cabeza y cuello. In: Oncología en pequeños animales. Buenos Aires: InterMédica, 2002. Cap.4, p.101-102. 
MORRISON, W.B. Cancer of the head and neck. In:

Cancer in dogs and cats: medical and surgical management. Baltimore: Lippincontt Williams and Wilkins, 1998. Cap.34, p.511-519.

RALLIS, T.S. et al. Immunohistochemical study of a granular cell tumor on the tongue of a dog. Vet Clin Pathol, v.30, n.2, p.62-66, 2001.
SCHOOFS, S.H. Lingual hemangioma in a puppy: A case report and literature review. J Am Anim Hosp Assoc, v.33, n.2, p.161-165, 1997.

WITHROW, S.J. Cancer of gastrointestinal tract. In: WITHROW, S.J.; MacEWEN, E.G. Small animal clinical oncology. 3.ed. Philadelphia: Saunders, 2001. Cap.18, p.305318 . 